\title{
A microcomputer-based technique for measuring response times in written protocols
}

\author{
TERESA A. SAWYER \\ Gettysburg College, Gettysburg, Pennsylvania \\ and \\ N. JOHN CASTELLAN, JR. \\ Indiana University, Bloomington, Indiana
}

\begin{abstract}
We describe a computer system that can be used to collect response times simultaneously with written protocols. It is applicable to tasks in which written protocols and associated response times are of interest.
\end{abstract}

Response time measures have not been as widely used in the study of problem solving as in other areas of cognitive psychology. Nevertheless, response time data have been critical in furthering our understanding of cognition and in the development of processing models, as is evident from perusing any contemporary textbook on cognitive psychology (e.g., Glass, 1986; Matlin, 1983).

A number of factors probably contribute to the infrequency of response time studies in the area of problem solving. Tasks used by researchers often do not lend themselves to the use of only a few discrete response alternatives, which are easily adapted to computerized data collection. For some tasks, such as mathematics problem solving, there may be only one correct response, but numerous correct ways of reaching it. In such problems, the method of reaching a solution may be of more interest than the response itself. Finally, people solve many types of problems with a pencil and paper and are uncomfortable solving the problems with mental calculations, while speaking aloud, or at a computer keyboard. Written protocols and response times gathered under such conditions may have low validity.

One method of overcoming these difficulties is to videotape subjects as they use pencil and paper to solve problems. However, taping subjects is not satisfactory, partly because the cameras and equipment may disturb the subjects, and partly because the response times from the videotapes must be hand scored and the results entered into a computer for further analysis.

In this paper, we describe a configuration of standard microcomputer components that permits the automatic collection and storage of response times for written protocols. This configuration has the advantages of permitting the

This system was designed initially to collect data for the first author's doctoral dissertation completed at Indiana University. The research was supported in part by National Institutes of Health Grant PHS S07 RR07031 to N. John Castellan, Jr., Indiana University. T. A. Sawyer's address is: Department of Psychology, Gettysburg College, Gettysburg, PA 17325. subject to use pen and paper and providing the experimenter with accurate, computer-recorded response times. Further advantages of this arrangement are that the experimenter may also obtain (1) response times for any subparts of the task that may be of interest, and (2) the X,Y coordinates of the subject's pen on the paper at any desired time and for any task.

This equipment configuration was developed for use in a study of algebra problem solving (Sawyer, 1984). However, the method is applicable to any area of research in which one wishes to collect computer-recorded response times and written protocols at the same time.

\section{EQUIPMENT}

The following equipment was used to collect data: an Apple II + computer, one disk drive, a monitor, a realtime clock, and an Apple Graphics Tablet with attached pen. The Apple Graphics Tablet is supplied with a noninking pen mechanism, which we replaced with an inking pen mechanism. ${ }^{1}$ The graphics tablet was fitted with a piece of cardboard with a rectangular opening cut in the middle to ensure that the writing paper was in the same place on the tablet for all pages for all subjects. Data were collected from one subject at a time.

\section{SOFTWARE}

The documentation provided with the graphics tablet provides the format and location of input from the tablet. This information includes the status of the pen (on or off the tablet) and the X,Y location of the pen if it is on the tablet. The clock may be read in order to obtain the current clock time, from which elapsed times are easily calculated. In pilot studies, we found that it was sufficient to record the location of the subject's pen once every second. ${ }^{2}$ If the subject's pen was not touching the tablet at the time of a query, the location at which the subject's pen next touched the tablet and the elapsed time since the last location were recorded. The times and locations were 
stored in memory until the subject completed one problem. The subject indicated that he/she was done by pressing the space bar on the computer keyboard; the computer program then stored the data on the disk.

The Appendix shows Apple BASIC commands that can be used to collect data. (All lines of code beginning with REM are simply comments for purposes of clarification; they do not affect the execution of the program.)

Lines 100-220 perform several initialization tasks. In Line 140, the variables X\%, Y\%, and TI are dimensioned. $\mathrm{X} \%$ and $\mathrm{Y} \%$ hold the $\mathrm{X}$ and $\mathrm{Y}$ coordinates of the pen on the graphics tablet, and TI holds the time elapsed since the last data point was sampled. After the initialization tasks are completed, Lines 260-330 display the question.

Next Lines 340-410 control the sampling rate and store the data for each sample point. The program cycles through these lines until the subject presses the space bar or 600 data points have been collected (a minimum of $10 \mathrm{~min}$ ). After the data are collected for one problem, they are stored on the diskette.

The program may be customized in many ways. For example, a user can change the maximum time for each question, present messages to the subjects at selected intervals (such as "TAKE A REST BREAK" after $5 \mathrm{~min}$ ), and change the content of the statement containing the question. The program can also be modified to present and time several questions in succession.

After the subject completes an experimental session, the data can be analyzed as the researcher desires. Not only can response time distributions be obtained, but the written protocol generation sequence can be reconstructed, because the data provide not only time information, but spatial coordinates as well. For example, a user can determine whether the subject progresses methodically from left to right and down a page or jumps around on the page.

\section{CONCLUSIONS}

The computer system described here can be used to collect response times simultaneously with written protocols. Use of this technique for data collection eliminates the tedious coding of response times from videotapes as well as the need to enter the data into a computer for analysis. This technique is applicable to the study of any task in which written protocols are used and response times are desired.

\section{REFERENCES}

Glass, A. L., Holyonk, K. J. (1986). Cognition (2nd ed.). New York: Random House.

Matun, M. (1983). Cognition. New York: Holt, Rinehart, \& Winston.

SAWYER, T. A. (1984). Algebra problem-solving strategies. Unpublished doctoral dissertation, Indiana University, Bloomington, IN.

\section{NOTES}

1. Available from Summagraphics Technology, Inc., P.O. Box 2046, Beaverton, OR 97075 . Simply disconnect the original stylus and connect the inking pen in its place. No other modification is necessary.

2. A sampling rate of one per second may not be appropriate for other studies. Pilot work should always be done to ensure that the sampling rate is appropriate for the particular task.

\section{APPENDIX}

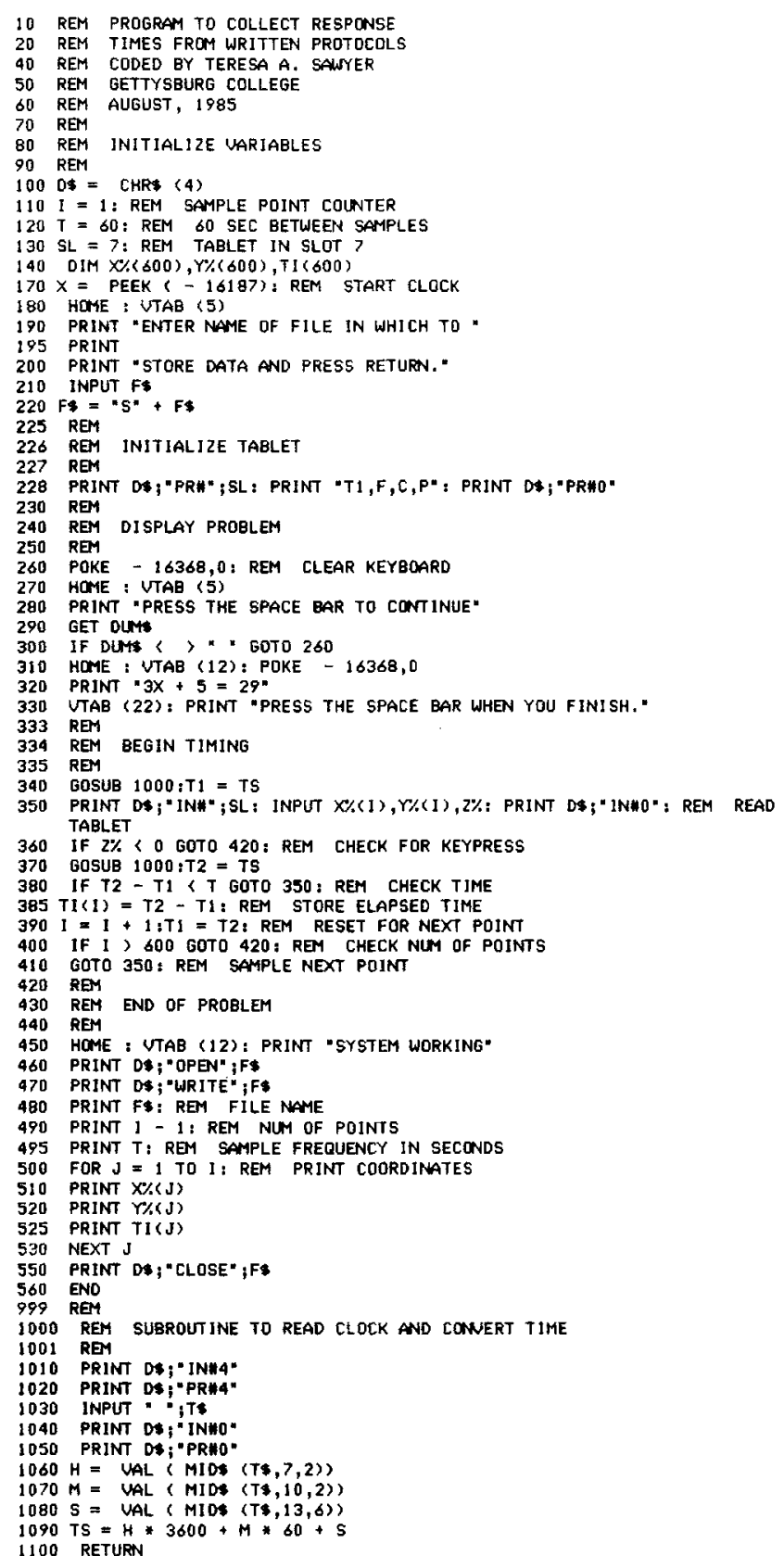

